\title{
Ontogeny of Pig Discrete Peyer's Patches: Expression of Surface Antigens
}

\author{
Levi H. C. MAKALA ${ }^{1)}$, Takenori KAMADA ${ }^{1)}$, Hideyuki NAGASAWA ${ }^{1)}$, , Ikuo IGARASHI ${ }^{1)}$, Kozo FUJISAKI ${ }^{1)}$, \\ Naoyoshi SUZUKI $^{1)}$, Takeshi MIKAMI ${ }^{1}$, Karin HAVERSON ${ }^{2)}$, Michael BAILEY ${ }^{2)}$, Christopher R. STOKES ${ }^{2)}$ and \\ Paul W. BLAND ${ }^{2}$
}

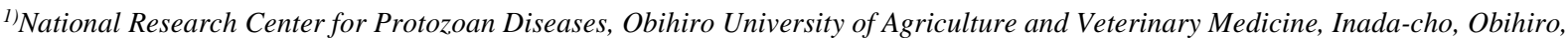
Hokkaido 080-8555, Japan, and ${ }^{2)}$ Division of Molecular and Cellular Biology, Department of Clinical Veterinary Science, University of Bristol, Langford House, Langford, Bristol BS40 5DU, UK

(Received 3 August 2000/Accepted 22 February 2001)

ABSTRACT. Leukocyte populations present in the discrete Peyer's patches (PP) of the pig were characterized from birth (Day 0) to day 35 after birth by immunohistochemistry and image analysis. Immediately after birth, cell membrane expression of CD2 and CD3, major histocompatibilty complex (MHC) class II (both SLA (swine leukocyte antigen) -DQ ${ }^{+}$and SLA-DR ${ }^{+}$), CD21, 74-22-15 and surface immunoglobulin (sIg) were all demonstrable. Computer assisted morphometric techniques were used to confirm the significant expansion of these cell populations from birth onwards. The distribution of the cell types was not random but suggested a preferential retention of cells at specific sites. This implies a degree of organization of immunological cells within the discrete PP, enhancing the potential to mount immune responses in the most efficient manner.

KEY WORDS: discrete Peyer's patch, ontogeny, surface antigen expression, swine.

J. Vet. Med. Sci. 63(6): 625-636, 2001

The development of peripheral lymphoid organs has been investigated morphologically by many authors $[6,8,26,29$, 30]. Most of these studies dealt with the lymphoid cells: B cells, T cells and plasma cells $[2,10]$. Other reports have been focused on the ontogeny of the non-lymphoid cells in peripheral lymphoid organs: macrophages, interdigitating cells, follicular dendritic cells, and reticulum cells [9, 29, 30]. Internally, lymphoid organs comprise several compartments [7], each with their own function [13] and characteristic cell population [31]. Within the Peyer's patches (PP), the cooperation between diverse types of lymphoid and nonlymphoid cells is essential for optimal immune response. The aim of this work was to provide information regarding interactions of lymphoid and non-lymphoid cells and to investigate the development of these cells in the pig discrete $\mathrm{PP}$, the major organized lymphoid structures involved in the induction of mucosal immune responses in the intestine.

\section{MATERIALS AND METHODS}

Animals: Samples were taken from newborn Large White/ Landrace hybrid piglets. All piglets were maintained in conventional conditions on a commercial diet (Willets, Bristol, UK). They ranged from 0-35 days of age and both sexes were used. Piglets were sacrificed at 0 (presuckled), 1, 2, 4, 6, 8, 10, 12, 14, 18, 21, 28 and 35 days after birth. From day 0 to day 12,3 piglets, 1 from each litter, were used, and from day 14 to day 35, 1 piglet from 1 litter was used. The piglets during this period (day 0-day 35) were not weaned.

\footnotetext{
* Correspondence to: Nagasawa, H., National Research Center for Protozoan Diseases, Obihiro University of Agriculture and Veterinary Medicine, Inada-cho, Obihiro, Hokkaido 080-8555, Japan.
}

Monoclonal antibodies: The following mouse monoclonal antibodies $(\mathrm{mAb})$ recognizing $\mathrm{T}$ cell markers and accessory cells were used: anti-pig CD2 [11]; anti-pig macrophage-granulocyte marker 74-22-15 [22]; anti-pig swine leukocyte antigen-DQ (SLA -DQ) [17]; anti-pig SLA-DR [16]; anti-pig CD21 (gift of Dr. Haverson, Bristol, UK); and anti-pig CD3 (gift of Dr. Young, Pilbright, UK).

Tissue collection and preparation: Tissue blocks approximately 5-15 $\mathrm{mm} \times 10 \mathrm{~mm}$, were excised and snap frozen in OCT cryoprotection medium (Tissue-Tek, London, UK) using liquid nitrogen-cooled isopentane. Tissues were labeled for identification by writing on the back of the corkmounting disk. The tissues were wrapped in aluminium foil and polybags to prevent dehydration and stored at $-70^{\circ} \mathrm{C}$ until further processing.

Peroxidase anti-peroxidase staining: Serial 4-6 $\mu \mathrm{m}$ frozen sections were cut onto multi-spot, poly-1-lysine precoated slides, dried for $1 \mathrm{hr}$ and fixed in ice cold acetone for $5 \mathrm{~min}$. All incubations were carried out at room temperature. Endogenous peroxidase activity was blocked using $0.1 \%$ periodic acid in saline [12] and back ground staining was reduced by pre-incubating with $10 \%$ normal rabbit serum/normal pig serum (in equal amounts) in phosphate buffered saline (PBS) for $30 \mathrm{~min}$. Sections were incubated with $50 \mu l$ each of optimized concentrations of mAb for $2 \mathrm{hr}$ in a humidity chamber. Affinity purified, biotinylated, rabbit and anti-mouse immunoglobulins (Dakkopatts, Oslo, Norway) were then added for $60 \mathrm{~min}$ (dilution 1:500), followed by an additional 30 min incubation with streptavidinbiotinylated horseradish peroxidase complex (Dakkopatts). The reaction was visualized using a $0.05 \%$ solution of diaminobenzidine tetrahydrochloride in $0.05 \mathrm{M}$ Tris- $\mathrm{HCl}$ ( $\mathrm{pH}$ 7.6). Between steps the slides were thoroughly washed in PBS. Sections were counterstained with Harris' haema- 


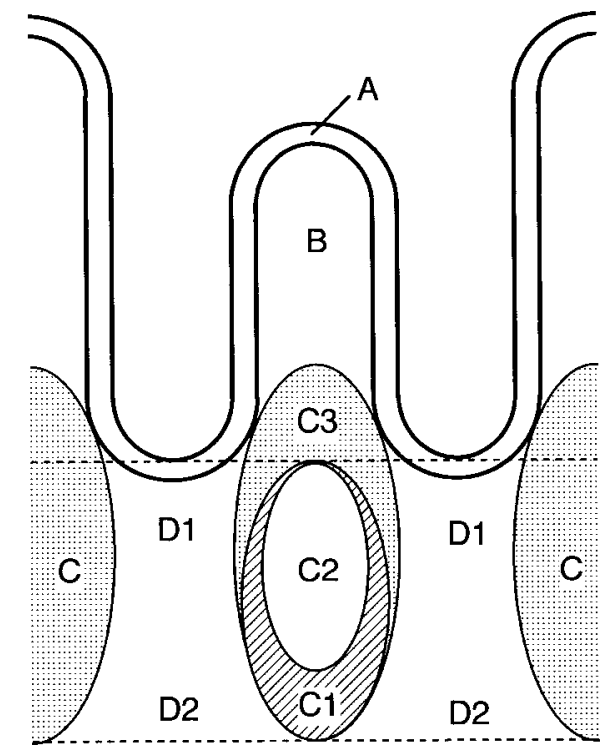

Fig. 1. Defination of standard Peyer's patch compartments used in this study. A-Lympoepithelium, B: Dome, C: Follicle, C1: Cortex, C2: Medulla, C3: Corona, D1: Upper interfollicular area, D2: Lower interfollicular area.

toxylin, dehydrated for 2 min each in 70, 90, 100\% alcohol and Histo-clear (National Diagnostics, Poole, UK) and mounted with DPX (BDH, Poole, UK).

Cell counts after peroxidase staining: Slides were observed using a Leitz DMR fluorescence microscope (Leica, Heerbrugg, Switzerland). The PP in each field of view was divided into arbitrary compartments, as defined in Fig. 1. Cells in each compartment were counted using Count Gem 1.2 for Windows software (ME Electronics Ltd., Reading, UK). Areas $\left(\mu \mathrm{m}^{2}\right)$ and length $(\mu \mathrm{m})$ of PP compartments were calculated using Gauge Gem 1.0 for Windows software (ME Electronics Ltd., Reading, UK). For each field, the area of each defined compartment was measured and the positively stained cells counted. Results are expressed as cells $/ \mathrm{mm}^{2}$. At least three randomly selected fields in each tissue sample were counted.

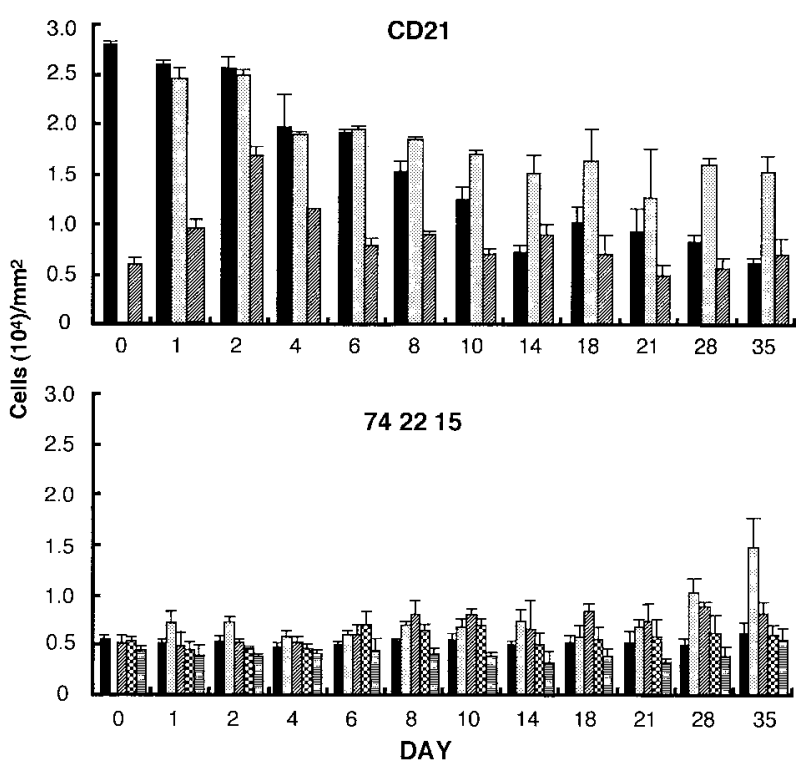

Cortex Medulla + Corona $\mathbb{Z}$ Dome

Upper interfollicular area 是 Lower interfollicular area

Fig. 2. Expression of surface antigens (74-22-15 and CD21) in Peyer's patch compartments. Values in the figure represent the mean of triplicate observations from 3 pigs (day 0-day 12) or means of triplicate observations from a single pig (day 14-day 35 ). Note that the follicle is not compartmentalized at day 0. Data for cortex, medulla or corona represent undifferentiated follicles at this time point.

\section{RESULTS}

Expression of surface antigens: Results of the expression of cell surface markers in the separate compartments of the discrete PP in the pig are summarized in Table 1.

CD21 expression: Results of CD21 expression are summarized in graphic form in Fig. 2 and pictorially in Figs. 3 and $4 . \mathrm{CD} 21^{+}$cells were localized from birth in the follicle and in the dome. At birth the follicle is not compartmentalized. Data for cortex, medula or corona of the follicle, represent undifferentiated follicles at this time point. Numbers of $\mathrm{CD} 21^{+}$cells in the dome increased rapidly from birth to

Table 1. Expression of cell surface markers in the separate compartments of the discrete Peyer's patches in the pig

\begin{tabular}{lcccc}
\hline Cell Surface marker & \multicolumn{4}{c}{ Compartments } \\
\cline { 2 - 5 } Specificity \& Clone & Lymphoepithelium & Dome & Follicle & Interfollicular area \\
\hline CD2 (MSA4) & $+*$ & + & + & + \\
CD3 (FY 1HZ) & + & + & + & + \\
CD21 (cc51) & $-* * *$ & + & + & - \\
SLA-DQ (274 3G8) & + & + & + & + \\
SLA-DR (40B) & + & + & + & + \\
SLA-DR (MSA3) & + & + & + & + \\
74-22-15 (wSwC3) & + l-** & + & + & - \\
SIg (K139-3E1) & - & - & + & + \\
\hline
\end{tabular}

* Seen in all Peyer's patches, ** Occasionally seen, *** Not seen. 

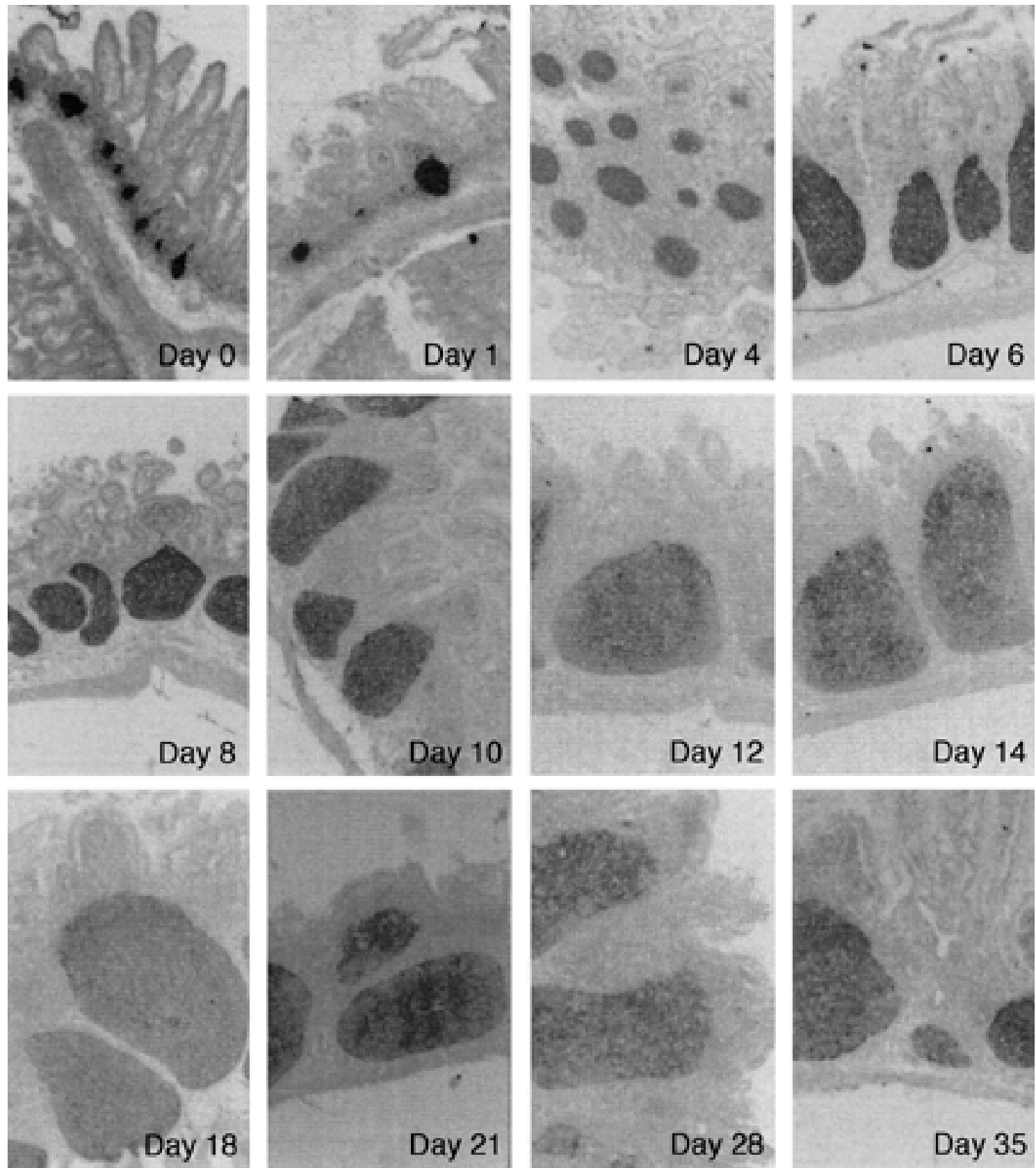

Fig. 3. Development of pig discrete Peyer's patches showing indirect immunoperoxidase staining of leukocytes expressing CD21 $(\mathrm{cc} 51) . \times 120$.

day 2 from 6,000 to 17,000 cell $/ \mathrm{mm}^{2}$, then showed a gradual decline and stabilized at $8,000-9,000$ cells $/ \mathrm{mm}^{2}$ between day 6 to day 14. In the medulla and corona regions of the follicle, there is an apparent slight decrease of cell numbers that stabilizes from day 6 to day 10 at levels of 15,00020,000 cells $/ \mathrm{mm}^{2}$. It is not possible to tell whether this decline in cell numbers in the medulla and corona of the follicle is a continuous trend because of the lack of data beyond day 35. Figure 4 shows a detailed distribution of $\mathrm{CD} 21^{+}$ cells in a PP from a 12-day old pig. CD $21^{+}$cells stained the follicle at high intensity with a few staining at lower intensity in the basal region of the dome.

74-22-15 expression: The follicle was undifferentiated at birth, however $74-22-15^{+}$cells were demonstrable at birth in the follicle. Between 4 and 10 days of age $74-22-15^{+}$ cells were localized in the cortex, medulla and corona of the follicle, the dome and lower and upper interfollicular areas (IFA). There were more numerous $74-22-15^{+}$cells in the 

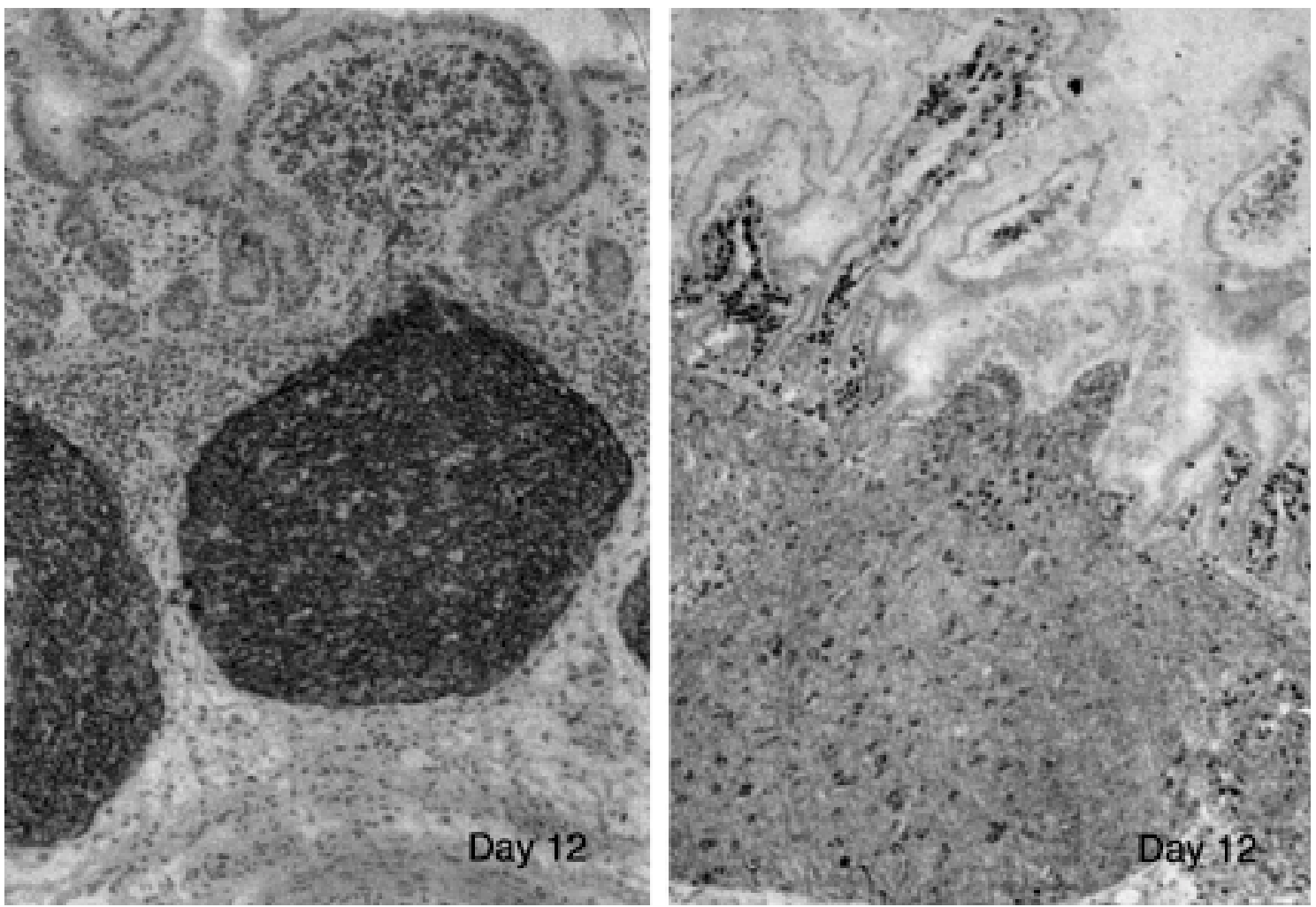

Fig. 4. Indirect immunoperoxidase staining of sections from discrete Peyer's patches showing a detailed distribution of leukocytes expressing: (A) CD21 (cc51); (B) 74-22-15 (wSwC3) at 12 days of age. $\times 150$.

medulla and the corona than in any other PP compartment. Results of $74-22-15^{+}$expression are summarized graphically in Fig. 2 and pictorially in Fig. 4. In Fig. 4, it can be seen that different cell types were stained with 74-22-15 at different intensities. Some cells in the follicle and in the dome were intensely stained dark brown whereas the rest of the cells were larger and less intensely stained and by day 8 the intensely stained cells concentrated in the dome and corona and medulla of the follicle. This result suggests the presence of more than one $74-22-15^{+}$cell type. There is a possible apparent increase in the number of $74-22-15^{+}$cells in the medulla and the corona of the follicle. However, it is not possible to tell whether this trend continues beyond day 35 because of insufficient data.

$C D 2$ and $C D 3$ expression: The expression of antigens recognized by $\mathrm{CD} 2$ and $\mathrm{CD} 3$ were taken together in this study because their distribution in PP compartments was the same. Results of CD2/CD3 antigen expression are summarized in graphic form in Fig. 5 and pictorially in Figs. 6, 7 and 8 . Figure 5 shows that cells of $\mathrm{CD} 2$ phenotype were relatively higher in number than those of $\mathrm{CD} 3$ phenotype. Cells of $\mathrm{CD} 2 / \mathrm{CD} 3$ phenotype were localized in the dome, medulla and corona of the follicle and lower IFA at low levels and the upper IFA at high levels. In addition, there was a greater number of $\mathrm{CD} 2^{+} / \mathrm{CD}^{+}$cells in the upper IFA at all time points than in other compartments. There was an apparent gradual decrease in the number of cells per unit area in the lower IFA which was stabilized by day 8 . Figsures 6,7 and 8 show that cells were arranged in a continuous zone within the upper IFA and the basal region of the dome.

SLA-DQ and SLA-DR expression: Surface membrane expressions of SLA-DQ and SLA-DR were also taken together because of the similar pattern of distribution in the PP compartments. The results of MHC class II expression are summarized in graphic form in Fig. 9 and pictorially in Figs. 10, 11 and 12. Cells of SLA-DQ/SLA-DR phenotype were localized in all PP compartments, with the highest levels in the corona of the follicle. It is interesting that MHC class II antigens start off at high levels from birth and stay stable to day 35. It is not possible to tell whether this trend is continuous beyond day 35 because of the lack of data beyond this time point. There were consistently greater numbers of MHC class $\mathrm{II}^{+}$cells, especially SLA-DR ${ }^{+}$in the upper IFA than in the lower IFA. As can be visualized in Figs. 10, 11 and 12, the density of class II staining in the upper IFA and the basal region of the dome was higher than in other PP compartments. The localization of intensely stained $\mathrm{MHC}$ class $\mathrm{II}^{+}$cells correlates with the localization of $\mathrm{CD} 2 / \mathrm{CD}^{+}$cells. 


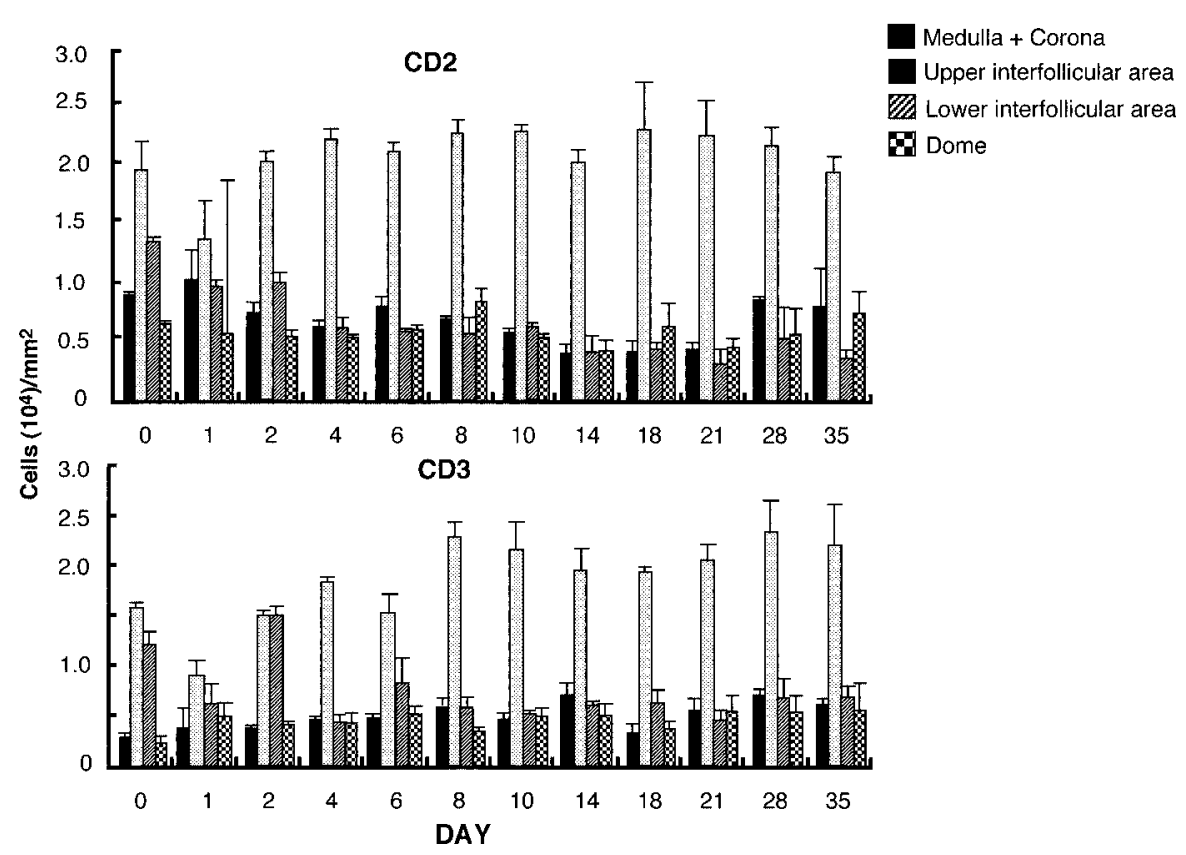

Fig. 5. Expression of surface antigens (CD2 and CD3) in Peyer's patch compartments. Values in the figure represent the mean of triplicate observations from 3 pigs (day 0 - day 12) or means of triplicate observations from a single pig (day 14day 35). Note that the follicle is not compartmentalized at day 0. Data for cortex, medulla or corona represent undifferentiated follicles at this time point.

\section{DISCUSSION}

Cell membrane expression for CD2 and CD3, MHC class II (SLA-DQ and SLA-DR), CD21, 74-22-15 and surface immunoglobulin ( $\mathrm{sIg}$ ) were all demonstrable at birth. The presence of $\mathrm{T}$ cells in the PP particularly CD2/CD3 phenotype suggests a potential for direct and local recognition of antigen. This requires the presence of accessory cells expressing MHC class II products and capable of antigen presentation (macrophages and dendritic cells). Cells staining for MHC class II (SLA-DQ and SLA-DR) and therefore potential candidates as antigen presenting cells (APC), appeared to occupy the same compartments as $\mathrm{CD} 2^{+}$and $\mathrm{CD}^{+}$cells in the PP (Fig. 4). This distribution where APC are localized in $\mathrm{T}$ cell areas is similar to that of analogous cells found in other species [19, 24, 25, 28, 33]. VegaLopez et al. [32], Rothkotter et al. [23] and Bianci et al. [3], reported low numbers of $\mathrm{CD} 2^{+}$cells in pig lamina propria (LP) at birth, and that these numbers increased significantly from 7 weeks after birth. On the contrary, this study has shown that in the PP of neonate pigs large numbers of $\mathrm{CD}^{+} /$ $\mathrm{CD}^{+} \mathrm{T}$ cells are present. Taken together, the results of this study and those of Vega-Lopez et al. [32] give an indication of the different roles the PP and LP in pigs may have in induction and regulation of immune responses. Thus, it can be hypothesized that the PP are major inductive sites of immune responses whereas LP is the major regulator of immune responses in the intestine.

Strongly MHC class $\mathrm{II}^{+}$cells (both SLA-DQ and DR) were already present in the discrete PP of newborn pigs. Sminia et al. [27] established that large MHC class $\mathrm{II}^{+}$cells in the rat may be dendritic cells as they have the ultrastructural characteristics of interdigitating cells (IDC). On the other hand, they may be B cells or macrophages. This may suggest that IDC/follicular DC home into the PP before birth. These results differ from those obtained for DC in the spleen [30] and the lymph node [9]. These authors reported that IDC only appear in the thymus-dependent areas of these organs about 2 weeks after birth. The intense staining for MHC class II antigens would support the possible role in antigen presentation.

The monocyte/granulocyte marker, 74-22-15 is expressed by a heterogeneous population of cells [11]. By immunoperoxidase staining of frozen sections of the pig, this study has demonstrated the presence of a dense layer of cells just beneath the lymphoepithelium that was stained with the anti-granulocyte/monocyte marker (mAb 74-2215). Additional staining suggested that these cells express MHC class II at high levels and an intracellular antigen of DC and B cells recognized by mAb cc51 (CD21). While there were $\mathrm{CD}_{2}{ }^{+}$and $\mathrm{CD}^{+}$cells in the dome by immunohistology, the pattern of staining did not suggest that the 74$22-15^{+}$cells were $\mathrm{T}$ cells, nor B cells. Taken together, these findings strongly argue that the dome of the PP is characterized by a layer of DC beneath the lymphoepithelium, which are poised for the capture and presentation of gut luminal antigens to PP T cells. Based on the information of the present study and the work of Kraal et al. [15] and Agger et 

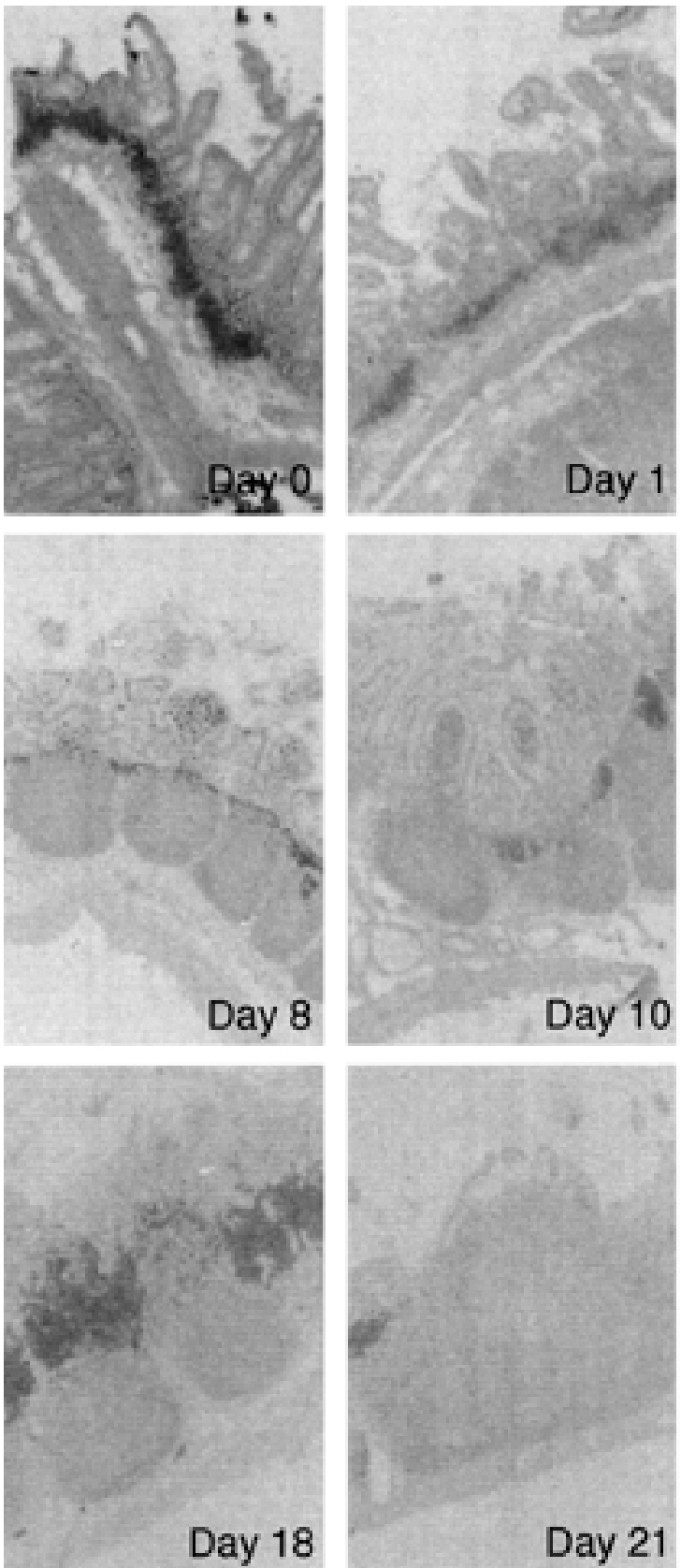
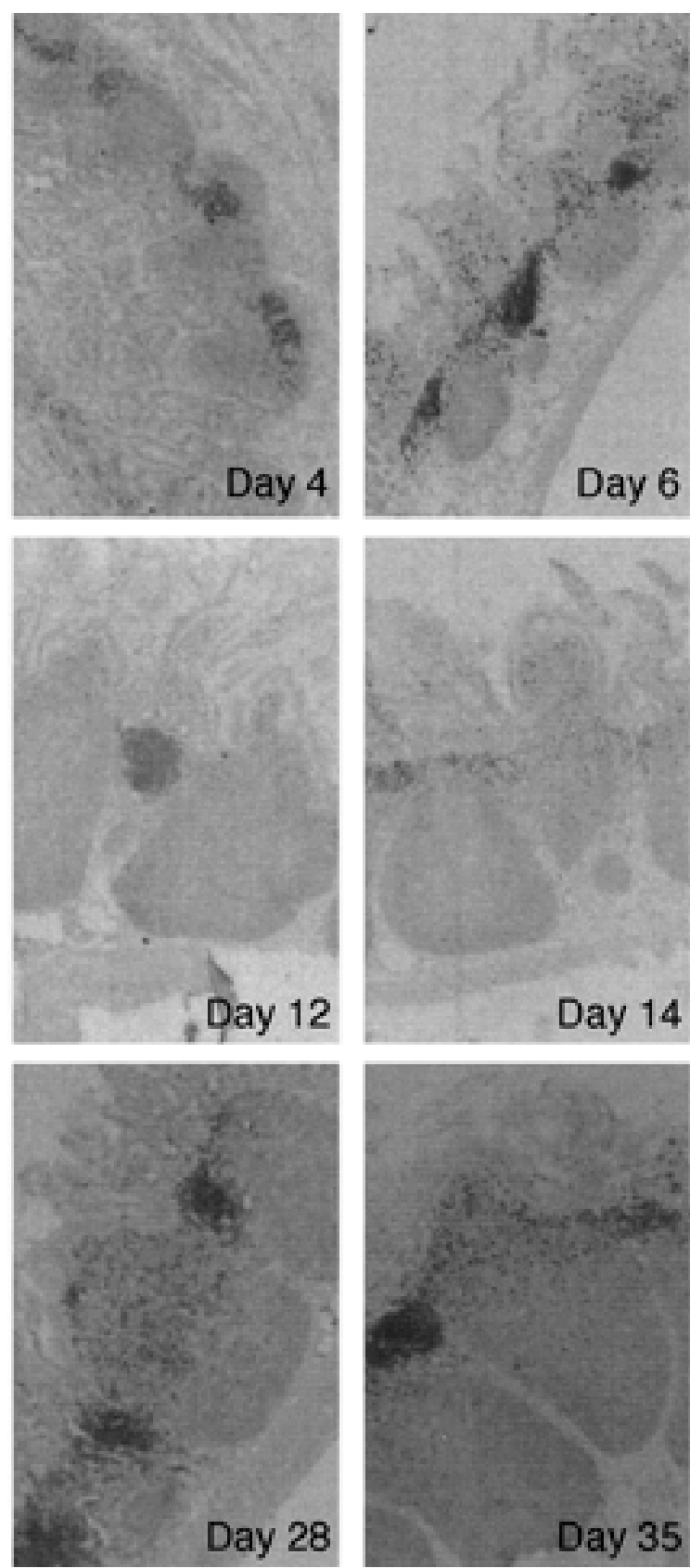

Fig. 6. Development of pig discrete Peyer's patches showing indirect immunoperoxidase staining of leukocytes expressing CD2 (MSA4). $\times 120$.

al. [1] who demonstrated the presence of 2 distinct splenic DC types in the mouse and Kelsall and Strobber [14] in the mouse PP, it appears quite likely that there are at least two different populations of DC in the pig PP. One is a population in the IFA, the other is the DC population in the basal region of the dome. This is as described by Metlay et al. [20] for spleen DC which lie in the direct path of migrating $\mathrm{T}$ cells. $74-22-15^{+}$cells were localized in the cortex, medulla, corona of the follicle, the dome and IFA. 74-22- $15^{+}$cells in the basal region of the dome were stained intensely, whereas those in IFA stained less intensely. The paucity of staining in these locations is relevant since MHC class $\mathrm{II}^{+}$cells were located in the same sites. The distribution of cells with 74-22-15 staining was similar to that reported for immunoglobulin containing cells $[4,5]$. The role of cells expressing this antigen is unclear but could include antigen handling, processing and presentation of antigen to $\mathrm{T}$ cells [18]. The dome hypothesized to be func- 

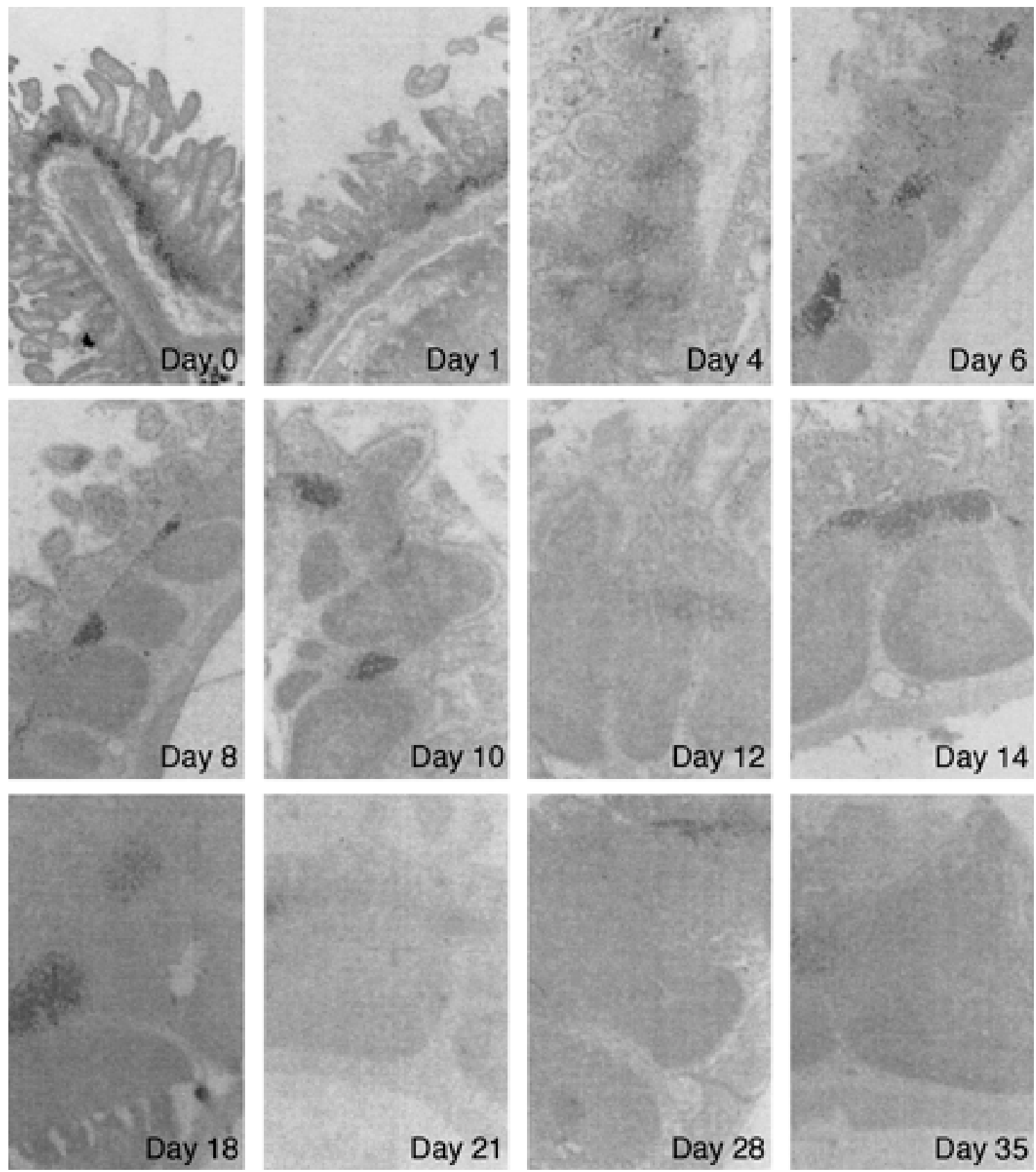

Fig. 7. Development of pig discrete Peyer's patches showing indirect immunoperoxidase staining of leukocytes expressing CD3 (FY 1HZ). $\times 120$.

tionally analogous to the marginal zone of the splenic white pulp, has been regarded as the main entrance route of antigen [21].

In conclusion, this study has demonstrated that the distribution of T cells and accessory cells within the discrete PP compartments is not random. This distribution suggests preferential retention of cells at specific sites. While this retention may be antigen driven, it implies a degree of orga- nization of immunological cells within the pig discrete PP, enhancing the potential to mount immune responses in the most efficient manner.

ACKNOWLEDGEMENTS. We are indebted to the Beit Trust, Woking, England, UK for financial support and to the National Research Center for Protozoan Diseases, Obihiro University of Agriculture and Veterinary Medicine, Hok- 

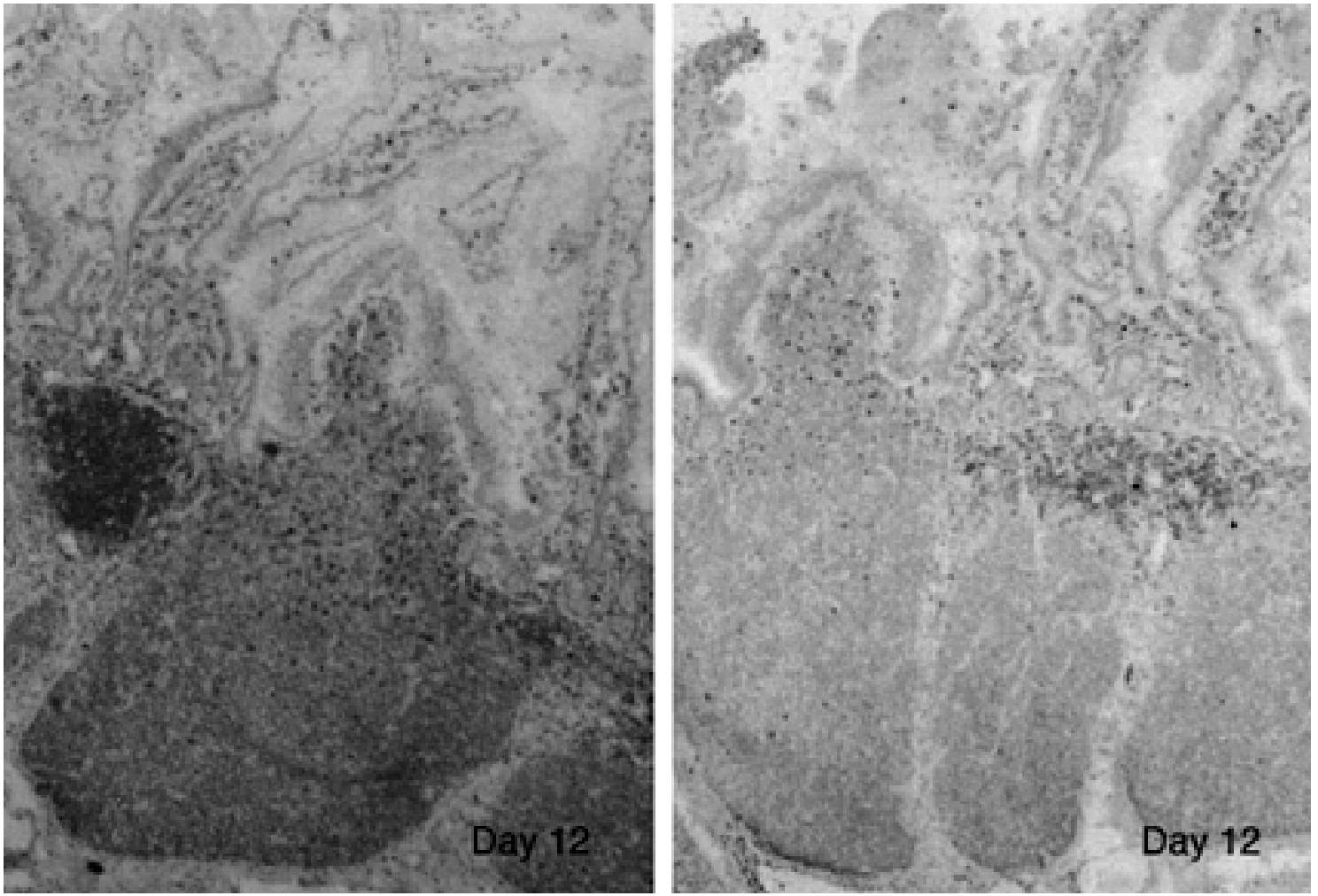

Fig. 8. Indirect immunoperoxidase staining of sections from discrete Peyer's patches showing a detailed distribution of leukocytes expressing: (A) CD2 (MSA4); (B) CD3 (FY 1HZ) at 12 days of age. $\times 150$.

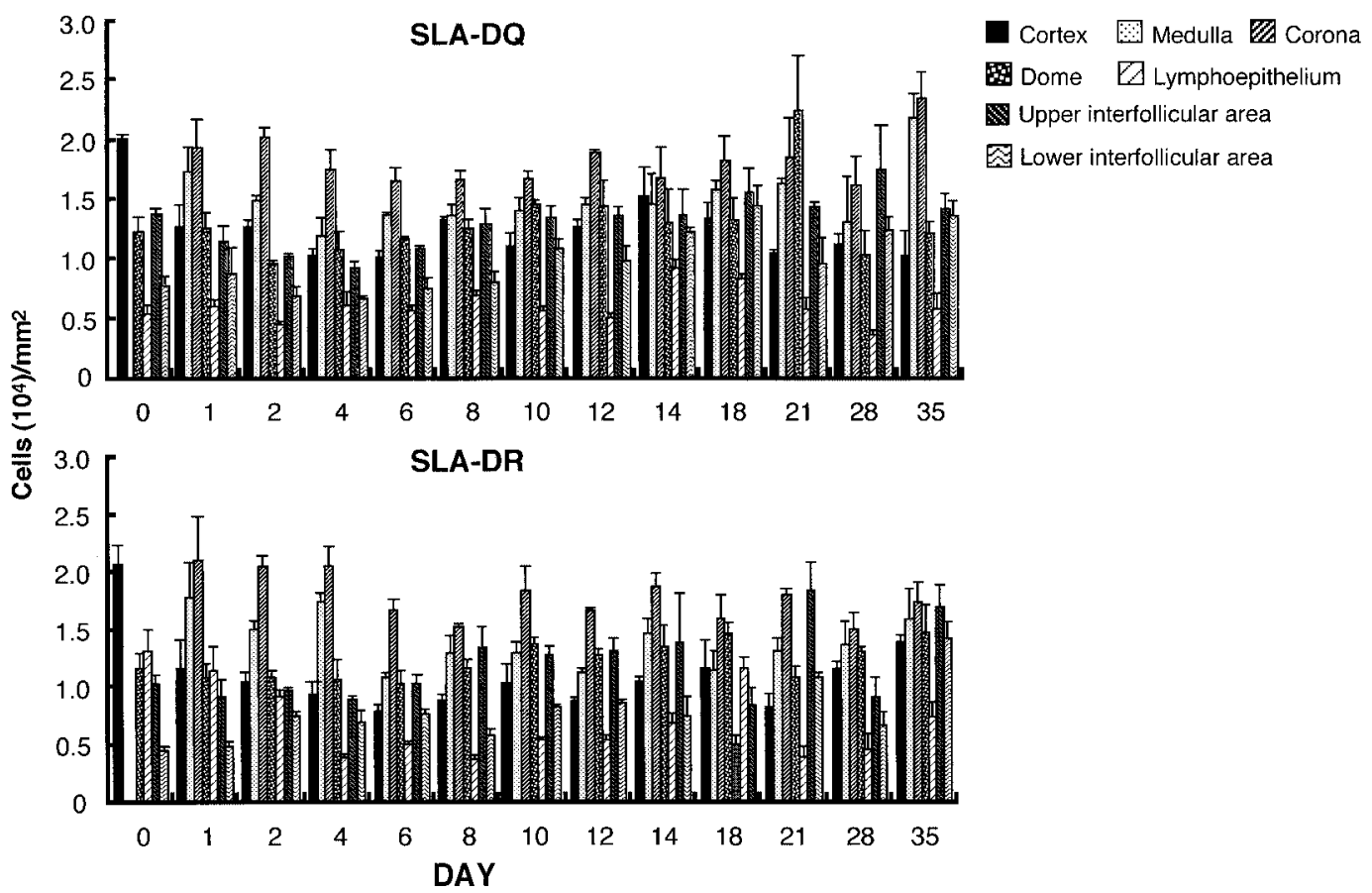

Fig. 9. Expression of surface antigens (SLA-DQ and SLA-DR) in Peyer's patch compartments. Values in the figure represent the mean of triplicate observations from 3 pigs (day 0-day 12) or means of triplicate observations from a single pig (day 14-day 35). Note that the follicle is not compartmentalized at day 0 . Data for cortex, medulla or corona represent undifferentiated follicles at this time point. 

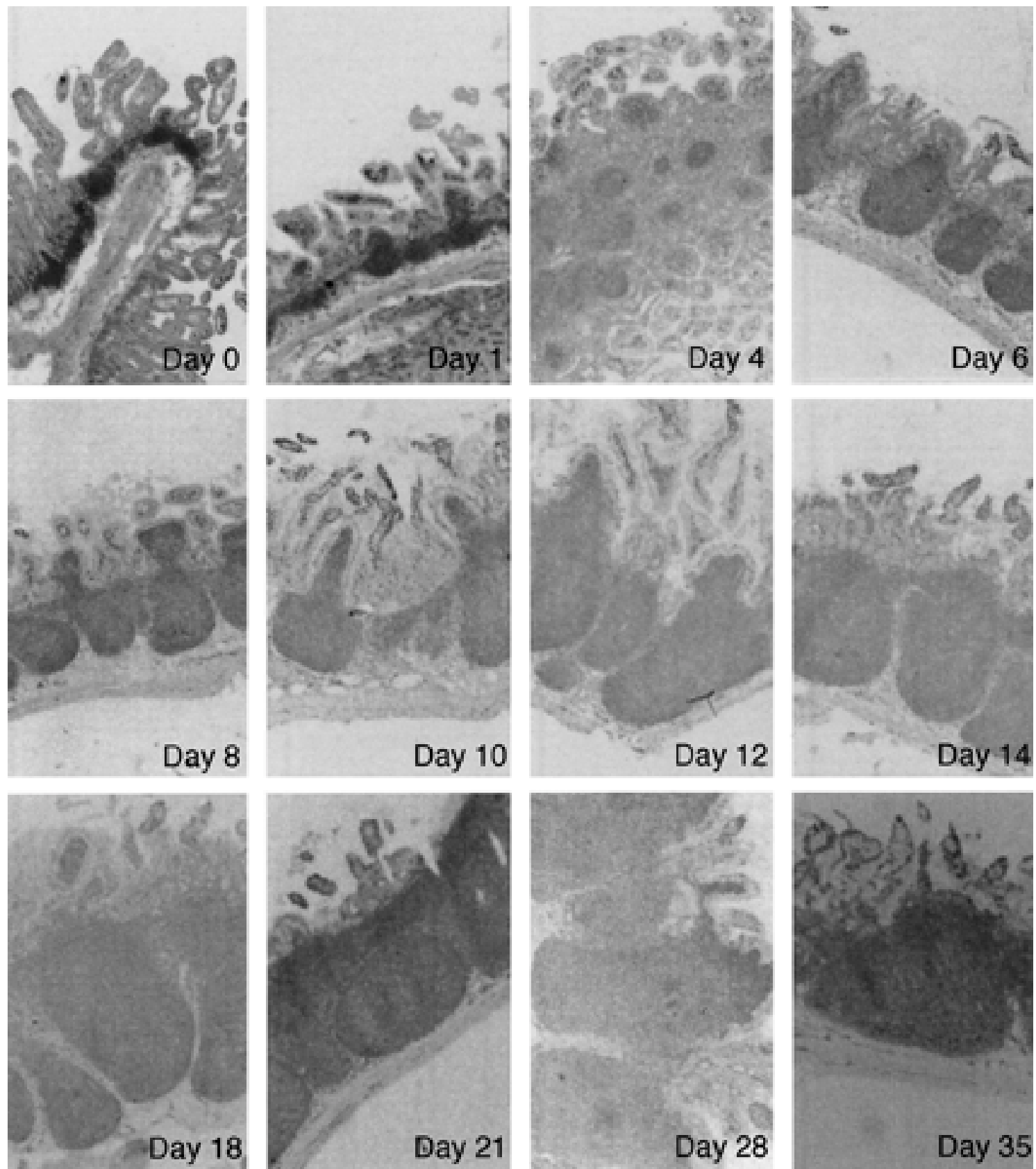

Fig. 10. Development of pig discrete Peyer's patches showing indirect immunoperoxidase staining of leukocytes expressing SLA-DQ (K274 3G8). × 120 .

kaido, Japan, for use of facilities to process this work. The first author is the Japanese Society for the Promotion of Science (JSPS) fellow, supported by funds from JSPS.

\section{REFERENCES}

1. Agger, R., Witmer-Pack, M., Romani, N., Stossel, H., Swiggard, J. P., Metley, J. P., Storozynsky, E., Freimuth, P. and Steinman, R. M. 1992. Two populations of splenic dendritic cells detected with M342, a new monoclonal antibody to an intracellular antigen of interdigitating dendritic cells and some B cells. J. Leukocyte Biol. 52: 34-42.

2. Allen, W. D. and Porter, P. 1977. The relative frequency and distribution of immunoglobulin-bearing cells in the intestinal mucosa of neonatal and weaned pigs and their significance in the development of secretory immunity. Immunology 32: 819824.

3. Bianchi, A. T., Zwart, R. J., Jeurissen, S. H. and MoonenLensen, H. W. 1992. Development of the B and T cell compartments in the porcine lymphoid organs from birth to adult life: 

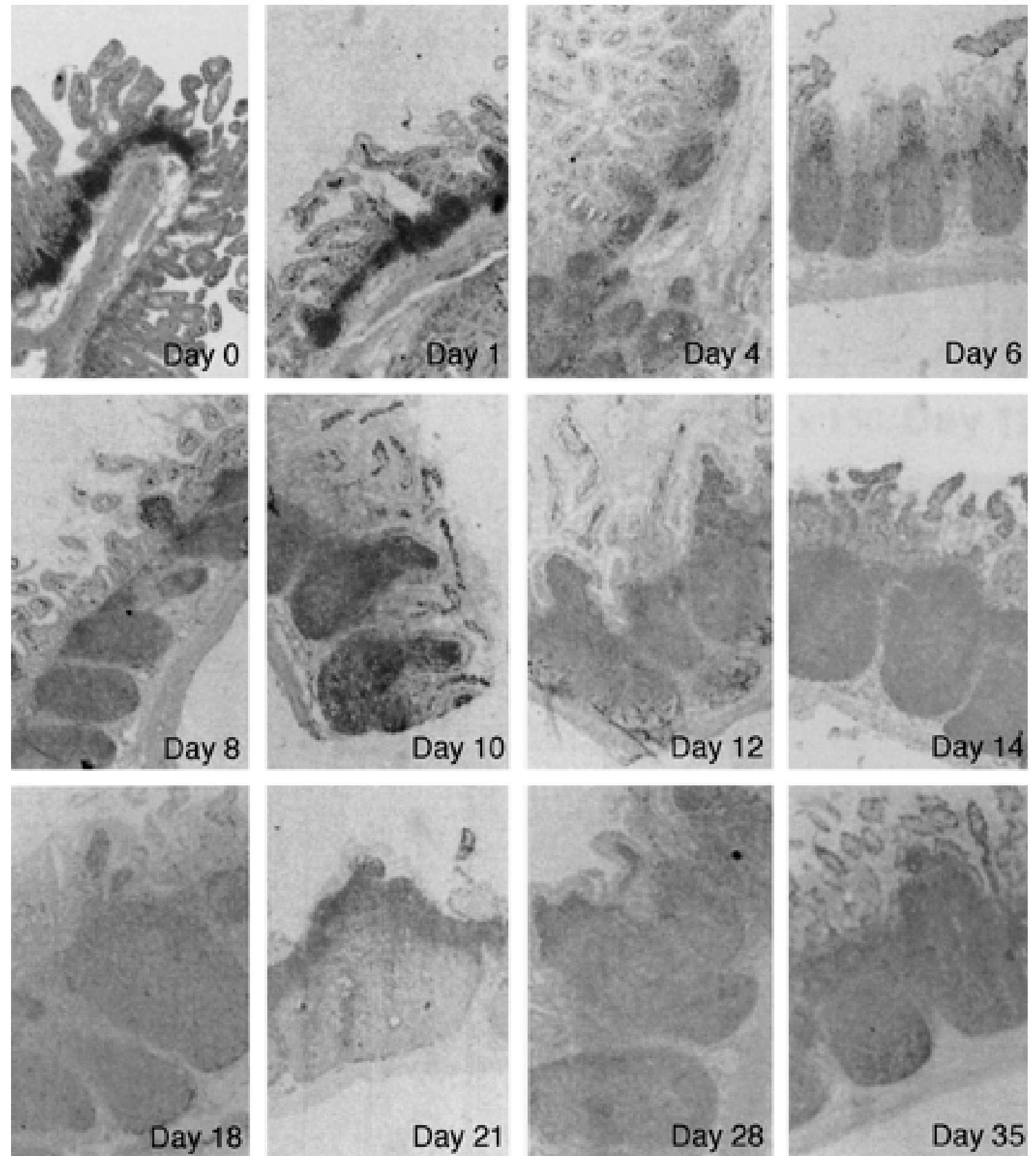

Fig. 11. Development of pig discrete Peyer's patches showing indirect immunoperoxidase staining of leukocytes expressing SLA-DR (MSA3). $\times 120$

an immunohistological approach. Vet. Immunol. Immunopathol. 33: 201-221.

4. Brown, M. G. and Bourne, F. J. 1976. Distribution of immunoglobulin containing cells in the alimentary tract, spleen and mensenteric lymph nodes of the pig demonstrated by peroxidase conjugated antisera to porcine immunoglobulins $\mathrm{G}, \mathrm{A}$ and M. Am. J. Vet. Res. 37: 9-13.

5. Brown, M. G. and Bourne, F. J. 1976. Development of immunoglobulin containing cells in the alimentary tract, spleen and mensenteric lymph nodes of the pig demonstrated by peroxidase conjugated antisera. Am. J. Vet. Res. 37: 1309-1314.

6. Bryant, B. J. 1974. The histo- and morphogenesis of lymphnodes: an interpretation of some mechanisms. J. Reticuloendothel. Soc. 16: 96-107.

7. Fossum, S. 1980. The architecture of the rat lymph nodes. II. Lymphnode compartments. Scand. J. Immunol. 12: 433-441.

8. Friedberg, S. H. and Weissman, I. L. 1974. Lymphoid tissue architecture. II. Ontogeny of peripheral $\mathrm{T}$ and $\mathrm{B}$ cells in mice: 

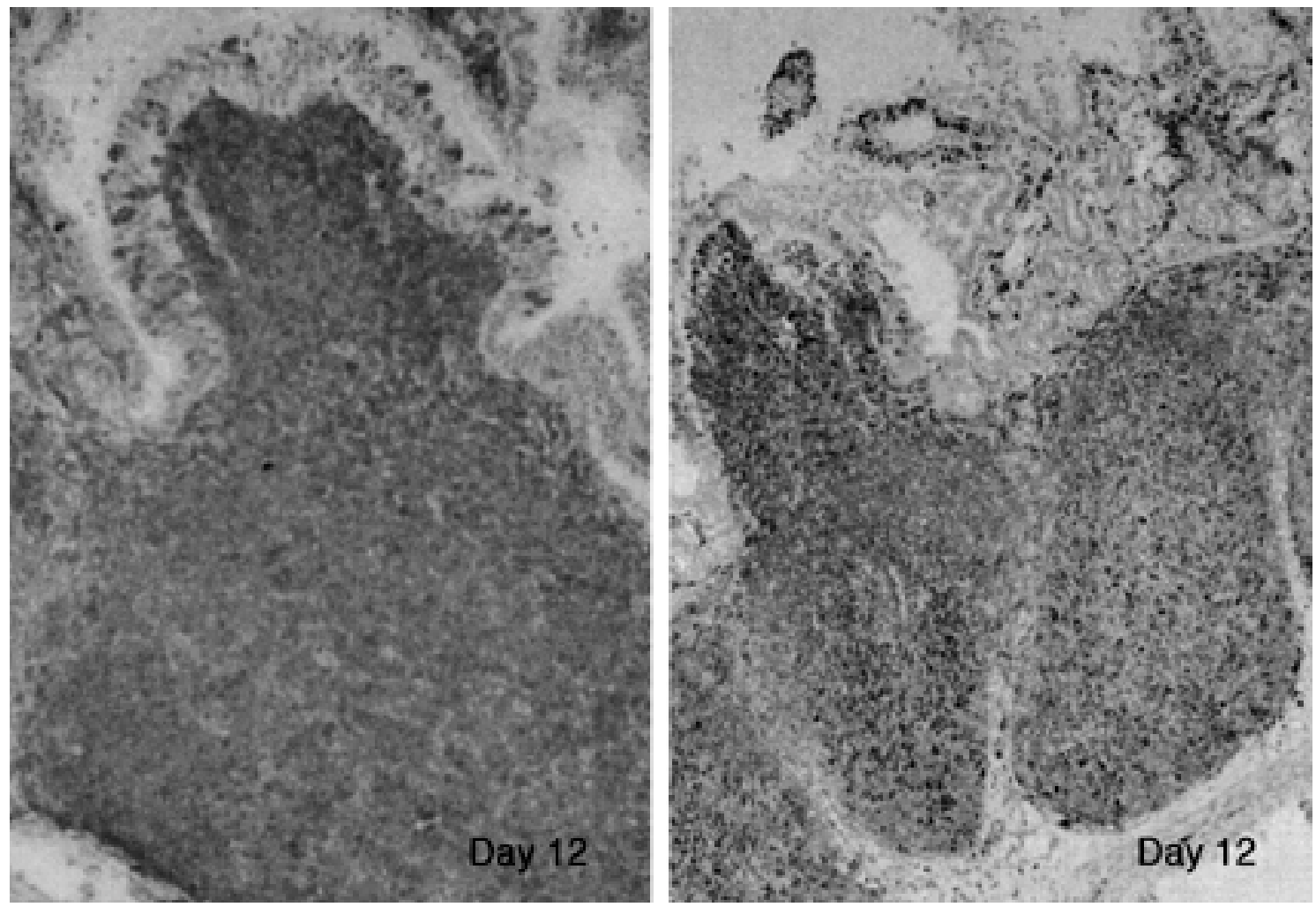

Fig. 12. Indirect immunoperoxidase staining of sections from discrete Peyer's patches showing a detailed distribution of leukocytes expressing: (A) SLA-DQ (K274 3G8); (B) SLA-DR (MSA3) at 12 days of age. $\times 150$.

evidence against Peyer's patches as the site of generation of B cells. J. Immunol. 113: 1477-1492.

9. Groscurth, P. 1980. Non lymphatic cells in the lymph node cortex of the mouse. II. Postnatal devopment of IDC and dendritic reticular cells. Pathol. Res. Pract. 169: 235-254.

10. Gutman, G. A. and Weissman, I. L. 1972. Lymphoid tissue archtecture: experimental analysis of the origin and distribution of T cells and B cells. Immunology 23: 465-479.

11. Hammerberg, C. and Schurig, G. 1986. Characterization of monoclonal antibodies directed against swine leukocytes. Vet. Immunol. Immunopathol. 11: 107-121.

12. Hittmair, A. and Schmid, K. W. 1989. Inhibition of endogenous peroxidase for the immunocytochemical demonstration of intermadiate filament proteins (IFP). J. Immunol. Methods 116: 199-205.

13. Kamperdijk, E. W. A., de-Leeuw, J.H. and Hoefsmit, E. C. M. 1980. Lymphnode macrophages and reticulum cells in the immune response. Cell Tissue Res. 227: 277-290.

14. Kelsall, B. L. and Strobber, W. 1996. Distinct populations of dendritic cells present in the subepithelial dome and $\mathrm{T}$ cell regions of the murine Peyer's patches. J. Exp. Med. 183: 237247.

15. Kraal, G., Breel, M., Janse, M. and Bruin, G. 1986. Langerhans' cells, veiled cells, interdigitating cells in the mouse recognized by a monoclonal antibody. J. Exp. Med. 163: 981-997.

16. Lunney, J. K., Osborne, B. A., Sharrow, S. O., Devaux, C., Pirres, M. and Sachs, D.H. 1983. Sharing of Ia antigens between species. IV. Interspecies cross reactivity of mono- clonal antibodies directed against polymorphic mouse Ia determinants. J. Immunol. 130: 2786-2793.

17. Lunney, J. K., Walker, K., Goldman, T., et al. 1994. Overview of the first international workshop to define swine leukocyte cluster of differentiation (CD) antigens. Vet. Immunol. Immunopathol. 43: 193-206.

18. Makala, L. H. C., Haverson, K., Stokes, C. R., Bailey, M. and Bland, P. W. 1998. Isolation and characterization of pig Peyer's patch dendritic cells. Vet. Immunol. Immunopathol. 61: 67-81.

19. Mayholfer, G., Pugh, C. W. and Barclay, A. N. 1983. The distribution, ontogeny and origin in the rat of Ia-positive cells with dendritic morphology and of Ia-antigen in epithelia with special reference to the intestine. Eur. J. Immunol. 13: 112122.

20. Metlay, J. P., Witmer-Pack, M. D., Agger, R., Crowley, M. T., Lawless, D. and Steinman, R. M. 1990. The distinct leukocyte itegrins of mouse dendritic cells as identified with a new hamster monoclonal antibody. J. Exp. Med. 171: 1753-1771.

21. Nieuwenhuis, P. 1971. On the Origin and Fate of Immunologically Competent Cells. Ph.D., Thesis, State University, Groningen, Wolters-Noordhoff, Groningen, The Netherlands.

22. Pescovitz, M. D., Lunney, J. K. and Sachs, D. H. 1984. Preparation and characterization of monoclonal antibodies reactive with porcine PBL. J. Immunol. 133: 368-375.

23. Rothkotter, H. J., Ulbrich, H. and Pabst, R. 1991. The postnatal development of the gut lamina propria lymphocytes: numbers, proliferation and $\mathrm{T}$ and $\mathrm{B}$ cell substs in conventional and germ- 
free pigs. Pediatr. Res. 29: 237-242.

24. Russell, G. J., Bhan, A. K. and Winter, H. S. 1990. The distribution of $\mathrm{T}$ and $\mathrm{B}$ lymphocyte populations and MHC class II expression in human foetal and postnatal intestine. Pediatr. Res. 27: 239-244.

25. Selby, W. S., Janossy, G., Goldstein, G. and Jewell, D. P. 1981. T lymphocyte subsets in human intestinal mucosa: the distribution and relationship to MHC-derived antigens. Clin. Exp. Immunol. 44: 453-458.

26. Sminia, T., Janse, E. M. and Plesch, B. E. C. 1983. Ontogeny of Peyer's patches of the rat. Anat. Rec. 207: 309-316.

27. Sminia, T., Janse, E. M. and Wilders, M.M. 1982. Antigen trapping cells in Peyer's patches of the rat. Scand. J. Immunol. 16: 481-485.

28. Trejdosiewicz, L. K., Malizia, G., Badr-el-Din, S., Smart, C. J., Oaks, D. J., Southgate, J., Howdle, P. D., Janossy, G., Poulter, L.W. and Losowsky, M. S. 1987. T cell and mononuclear phagocyte populations of the human small and large intestine. p. 465. In: Recent Advances in Mucosal Immunology (Mestecky, J. R., Mcghee, J., Bienenstock, J. and Ogra, P. L. eds.), Plenum Press, NY.
29. Veerman, A. J. 1974. On the interdigitating cells in the thymusdependent area of the rat spleen: a relationship between the mononuclear phagocytes system and T lymphocytes. Cell Tissue. Res. 148: 247-257.

30. Veerman, A. J. 1975. Postnatal development of the white pulp in the rat spleen and the onset of immunocompetence against a thymus-dependent and thymus-independent antigen. Z. Іттиnitats. Forsch. Exp. Klin. Immunol. 150: 45-59.

31. Veerman, A. J. and Van Ewijk, W. 1975. White pulp compartments in the spleen of rats and mice: a light and electron microscopic study of lymphoid and non-lymphoid cells types in $\mathrm{T}$ and B cell areas. Cell Tissue Res. 156: 417-441.

32. Vega-Lopez, M. A., Bailey, M., Telemo, E., Stevens, K. and Stokes, C. R. 1993. Immune cell distribution in the small intestine of the pig: immunohistological evidence for an organized compartmentalization in the lamina propria. Vet. Immunol. Immunopathol. 37: 49-60.

33. Vega-Lopez, M. A., Bailey, M., Telemo, E. and Stokes, C. R. 1995. Effects of early weaning on the development of immune cells in the pig intestine. Vet. Immunol. Immunopathol. 44: 319-327. 